\title{
IDENTIFICATION OF GERREID SPECIES (ACTINOPTERYGII: PERCIFORMES: GERREIDAE) FROM THE PACIFIC COAST OF MEXICO BASED ON SAGITTAL OTOLITH MORPHOLOGY ANALYSIS
}

\author{
José DE LA CRUZ-AGÜERO*, Francisco Javier GARCÍA-RODRÍGUEZ, \\ Gustavo DE LA CRUZ-AGÜERO, and Bertha Paulina DÍAZ-MURILLO
}

\author{
Instituto Politécnico Nacional, Centro Interdisciplinario de Ciencias Marinas, Colección Ictiológica. \\ La Paz, Baja California Sur, México 23096
}
De La Cruz-Agüero J., García-Rodríguez F.J., De La Cruz-Agüero G., Díaz-Murillo B.P. 2012. Identification of gerreid species (Actinopterygii: Perciformes: Gerreidae) from the Pacific coast of Mexico based on sagittal otolith morphology analysis. Acta Ichthyol. Piscat. 42 (4): 297-306.

\begin{abstract}
Background. Although the species of the family Gerreidae have been subjected to many studies, their taxonomy at specific- and sometimes generic levels is still confusing. To contribute to the clarification of the taxonomy of the Mexican Pacific mojarras, the morphology of sagittal otoliths among six species of mojarras (Diapterus brevirostris, Eugerres lineatus, Eucinostomus dowii, E entomelas, E. currani, and Gerres cinereus) was compared using size and shape descriptors. Otolith shape has long been known to be species-specific but this has not been tested in species of the family Gerreidae. Therefore, our goal was to explore the effectiveness of otolith descriptors for identifying gerreid fish at species level.

Materials and methods. Gerreid fish were captured between January 2009 and January 2010, off the Pacific coast of Mexico. The right- and left sagittae of 160 individuals were extracted for analysis. Size and shape descriptors considered in the presently reported analysis were: surface area, perimeter, length, width, rectangularity, ellipticity, roundness, circularity, aspect ratio, form-factor, Feret length, Feret width, Feret maximum, Feret minimum, diameter maximum, diameter minimum, diameter mean, ratio maximum, and ratio minimum. Other measurements were made in the otolith region of sulcus acusticus, such as: cauda length, ostium length, ostium width, sulcus length, and rostrum width. Canonical discriminant analysis on otoliths morphology was used to identify differences between species.

Results. Rectangularity, roundness, otolith length, and Feret length were the main otolith descriptors that explain the inter-specific variability. Significant differences (Wilks' lambdas $(\lambda), P<0.001$ ), high canonical correlation coefficients, and also a high classification success (overall mean $>90 \%$ ) allowed the separation of the species by using discriminant functions. Results from both $G$-test and Cohen's kappa procedure confirmed the high rates of classification success obtained by the discriminant analysis.

Conclusion. These results suggest the usefulness of otolith morphology for differentiation of Gerreidae species from Mexican Pacific waters, thereby demonstrating that otolith shape is species-specific. Otolith morphology descriptions provided in this study is presented for the first time for the species included.
\end{abstract}

Keywords: Gerreidae, canonical discriminant analysis, otolith morphology, Mexico

\section{INTRODUCTION}

Fish family Gerreidae, commonly known as mojarras or silver-biddies is one of the most representative groups in aquatic systems of tropical and subtropical areas of the world (Yáñez-Arancibia 1980, Matheson and McEachran 1984). Gerreidae comprises some 100 nominal species grouped in eight genera (Eschmeyer 2012), two of which are monotypic: Pentaprion and Ulaema. Currently, two species are considered valid in Parequula, eight in Eugerres, six in Diapterus, 10 in Eucinostomus, and 28 in Gerres (Froese and Pauly 2012). Although, since the 19th century, the mojarras have been subject of many studies, mostly focused on ecological issues, their taxonomy at specific- and sometimes generic levels is still confusing (De La Cruz-Agüero and Galvan-Magaña 1993, Chen et al. 2007). At present, the taxonomic status of more than 50 nominal species, mainly included in the last three mentioned genera, has not recently been revised and some gerreid taxa still have recognition problems and their taxonomic validity is questionable, e.g.: Ulaema lefroyi (Goode, 1874); Eucinostomus havana (Nichols, 1912); Diapterus aureolus (Jordan et Gilbert, 1882); Eugerres periche (Evermann et Radcliffe, 1917).

\footnotetext{
${ }^{*}$ Correspondence: Dr. José De La Cruz-Agüero, Instituto Politécnico Nacional, Centro Interdisciplinario de Ciencias Marinas, Colección Ictiológica, Avenida Instituto Politécnico Nacional s/n, Colonia Playa Palo de Santa Rita, La Paz, Baja California Sur, México 23096, phone: 52 (612) 1225344 ext. 82407 , fax: 52 (612) 122 5322, e-mail: jcruz@ipn.mx.
} 
Although gerreid fish have an important value for human consumption in tropical and subtropical regions, separate catch statistics are not reported for the majority of species and the landings are often summarized as mojarras. This lack of species-specific data is partly due to the difficulty in distinguishing many of the species (De La Cruz-Agüero and Galvan-Magaña 1993). Traditionally, identification of the Gerreidae taxa has been difficult and time consuming, because of the subjectivity of characteristics and overlap of meristic and morphometric characters provided in taxonomic keys (Bussing 1995). Other contributions to this taxonomic problem in the family are the inadequate or incomplete descriptions of type materials, their poor current condition, loss of some of them, and lack of published taxonomic reviews (Yáñez-Arancibia 1980).

Otoliths, the calcium carbonate structures located in fish inner ear, have been used as an auxiliary characteristic for identification of fishes in paleoichthyology (Nolf 1995) and stock recognition in fisheries management (Begg and Brown 2000, Tuset et al. 2003a, Neves et al. 2011), as well as a useful morphological character in taxonomy (Torres et al. 2000a, Tuset et al. 2006), systematics (Lombarte et al. 1991, Smale et al. 1995, Volpedo and Echeverría 2000), and food habits analysis (Radhakrishnan et al. 2010). Otolith shape has long been known to be species-specific (L'Abée-Lund 1988) and less variable in growth than body growth, presumably because otoliths are internal organs contributing to audition and balance (Lord et al. 2012), although its morphology can often vary geographically within a species (Lombarte and Lleonart 1993). In the majority of teleost species, sagittal otoliths are the largest pair, so they are the structures most frequently used in comparative studies because of the relative ease with which this structure can be reached (Nolf 1995). In addition, it has been established that from the three otolith pairs, sagittae is the pair with highest interspecific variation (Tuset et al. 2003b).

Comparison of otolith morphology using size parameters and shape indices of six Gerreidae species that inhabit the west Pacific coast of Mexico, including the Gulf of California was performed in the frames of the presently reported study. These species are important in small-scale artisanal fisheries of the country (Aguirre-León and Yáñez-Arancibia 1986): the short-beaked mojarra, Diapterus brevirostris (Sauvage, 1879); streaked mojarra, Eugerres lineatus (Humboldt, 1821); Dow's mojarra, Eucinostomus dowii (Gill, 1863); dark-spot mojarra, Eucinostomus entomelas Zahuranec in Yáñez-Arancibia, 1980; Pacific flagfin mojarra, E. currani Zahuranec in Yáñez-Arancibia, 1980; and yellow fin mojarra, Gerres cinereus (Walbaum, 1792). Our main objective was to assess otolith morphology variation to test the hypothesis that otolith morphology distinguishes gerreid fish at species level and therefore, to contribute in highlighting mojarras taxonomy in the Pacific coast of Mexico.

\section{MATERIALS AND METHODS}

The right and left sagittae of 160 individuals were extracted for analysis, although sometimes it was not possible to obtain the complete pairs (230 sagittae in total). The gerreid fish were captured between January 2009 and January 2010, from the Pacific, off three Mexican states (Fig. 1): Baja California Sur (La Paz Bay, Magdalena Bay, and Espiritu Santo Island), Sinaloa (Mazatlan har-

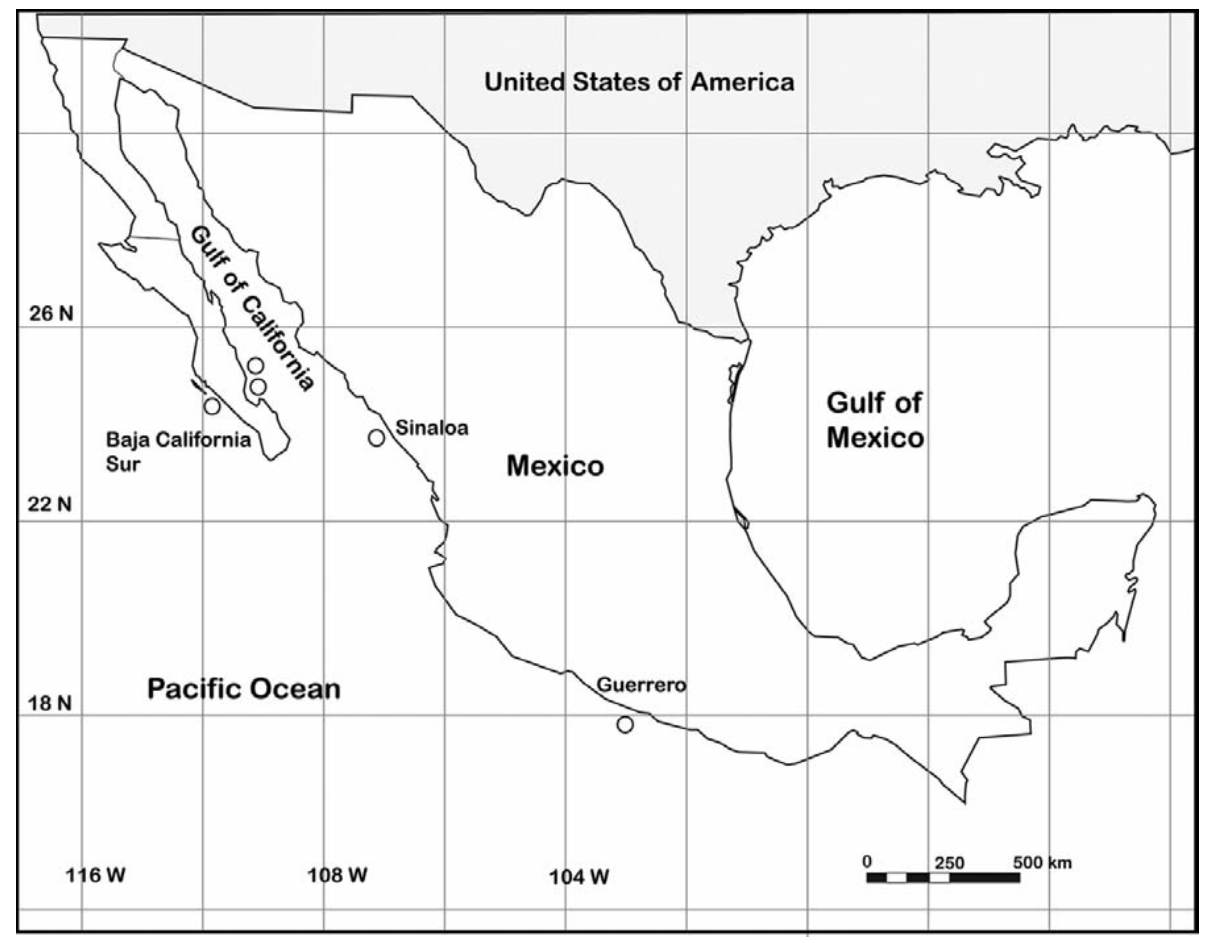

Fig. 1. Sampling locations (hollow circles) of species of the fish family Gerreidae in the states of Baja California Sur, Sinaloa, and Guerrero in the west coast of Mexico (January 2009 and January 2010) 
bour), and Guerrero (Acapulco harbour). These specimens came from artisanal catches of local fisheries and occasional samples by the authors. Each fish was measured to the nearest $\mathrm{mm}$ (standard length, SL). Otoliths were placed in distilled water just after extraction to clean them and stored in labelled glass vials. All fish and sagittae (hereafter called otoliths) were deposited and catalogued in the fish collection of the Centro Interdisciplinario de Ciencias Marinas (CICIMAR-IPN) at La Paz, B.C.S., Mexico.

Considering all sampled fish, body size varied from $55 \mathrm{~mm}$ $\mathrm{SL}$ in D. brevirostris and $245 \mathrm{~mm} \mathrm{SL}$ in $G$. cinereus (Table 1). The sex was not considered separately because gerreid fish do not have sexual dimorphism (De La Cruz Agüero and Galvan-Magaña 1993). Digital images of each pair of otoliths by species were taken with an Olympus ${ }^{\circledR}$ stereo-microscope model SZ61 fitted with an adapter for digital camera Olympus ${ }^{\circledR}$ SP-320 with $3 \times$ optical zoom and a light source Olympus ${ }^{\circledR}$ SZ2-LGBST to highlight edges of the structures. The otoliths were positioned systematically with the sulcus acusticus up and the rostrum pointing to the left before capture as bright objects on dark background.

Digitized images of each otolith were analyzed using the Image Pro Plus ${ }^{\circledR}$ program (version 6.0) to measure surface area (Ao; units in $\mathrm{mm}^{2}$ ), perimeter (Po), length (Lo), width (Wo), diameter maximum (Dmx), diameter minimum $(\mathrm{Dmn})$, Diameter mean (Dm), ratio maximum (Rmx) and ratio minimum (Rmn) - all of them taken to the nearest 0.01 $\mathrm{mm}$. Such measurements were used to calculate dimensionless shape indices (Tuset et al. 2003b, Ponton 2006, Pothin et al. 2006) which are independent from differences in otolith size (Tuset et al. 2006, Lord et al. 2012), which include (Fig. 2, Table 2): rectangularity, roundness, circularity, form-factor, ellipticity, and aspect ratio. Previously, to calculate roundness, rectangularity, and ellipticity it was necessary to obtain Feret length (Fl), Feret width (Fw), and its two components: Feret maximum (Fmx) and Feret minimum (Fmn) (see Pertusa 2003). Other measurements were made in the otolith region that is associated with the sensory macula: sulcus acusticus (e.g., sulcus length $(\mathrm{Sl})$, cauda length (CL), ostium length (OL), ostium width (OW), and rostrum width $(\mathrm{RW})$.

We used a Friedman's Q test (FQT), a non-parametric test used to compare repeated observations on the same subjects belonging to three or more paired groups, to detect differences between sulcus acusticus ratios by species. The FQT makes no assumptions for data distribution (e.g., normality or homoscedasticity of variance) (Zar 2009).

Canonical discriminant analysis (CDA) was run for all fish with both otoliths pooled together as recommended by Morat et al. (2012), and used to assess whether species can be distinguished between each other based on otolith descriptors or not. Percentage of correct assignment of individuals, calculated within classification matrix, can then be used as a morphometric measurement of similarity between taxa and as an evidence for the a-priori established taxonomic structure (e.g., conventional identifica- tion produced by taxonomic keys). Quadratic Mahalanobis distances (MD) and their approximations to the $F$-statistics were used to assess significant differences between species centroids in the multivariate space. Also a dendrogram was constructed by hierarchical cluster analysis (UPGMA), based on the Euclidian distance of MD values to assess the degree of similarity between Gerreidae species by otolith descriptors.

Statistical significance of CDA was assessed by Wilks' lambda $(\lambda)$ test. Values close to zero indicate a good model fit and values $\approx 1$ indicate lower discrimination power (Klecka 1980, Lord et al. 2012). Another way to judge the relevance of a discriminant function is by examining the canonical correlation coefficient ( $r^{*}$; Klecka 1980). If the groups are no very different on the variables being analyzed, then all of the correlations will be low. Classification efficiency (e.g., estimate error rates in CDA) was cross-validate according to Lachenbruch and Mickey (1968). The bias of the classification was determined with the Cohen's kappa ( $\kappa)$ coefficient, which estimates the improvement over chance of the percent corrected classification rates (Tuset et al. 2003b). Values of $\kappa$ range from 0 to 1 , with zero indicating that the discriminant analysis yielded no improvement over chance, while a $\kappa$ of 1 occurs only with perfect agreement (Titus et al. 1984). The $\kappa$ values were scaled up to a percentage, and the prior probability of classification was equal for all groups. Finally, a $G$-test of independence was used to test agreement between observed classification rates and expected classification rates (Tuset et al. 2003a). All statistical analyses were performed in $\mathrm{XLStat}^{\circledR}$ 2009, a statistical plug-in for MS Excel ${ }^{\circledR} 2007$ spreadsheet program. Significance level was set at 0.05 for all statistical tests used.

\section{RESULTS}

The gross morphology and morphometry of the otolith are described by species according to Tuset et al. (2003a) and Volpedo et al. (2008), and all ratios are expressed as the average (see also Fig. 2 and Table 2):

Diapterus brevirostris. Otolith shape: oblong or semicir-

Table 1

Details of samples of the fish family

Gerreidae used in the otolith morphology analysis for species identification

\begin{tabular}{lrrrc}
\hline \multirow{2}{*}{ Species } & $N$ & $n$ & \multicolumn{2}{c}{ Standard length [mm] } \\
\cline { 4 - 5 } & & & Mean & Range \\
\hline Diapterus brevirostris & 22 & 37 & 156.8 & $55.0-170.0$ \\
Eugerres lineatus & 27 & 36 & 166.0 & $79.0-200.0$ \\
Eucinostomus dowii & 12 & 21 & 162.0 & $120.0-168.0$ \\
Eucinostomus entomelas & 36 & 43 & 178.0 & $83.0-195.0$ \\
Eucinostomus currani & 28 & 45 & 140.3 & $60.0-170.0$ \\
Gerres cinereus & 35 & 48 & 223.0 & $110.0-245.0$ \\
\hline Total & 160 & 230 & & \\
\hline
\end{tabular}

$N=$ number of individuals, $n=$ number of otoliths (sagittae) examined. 

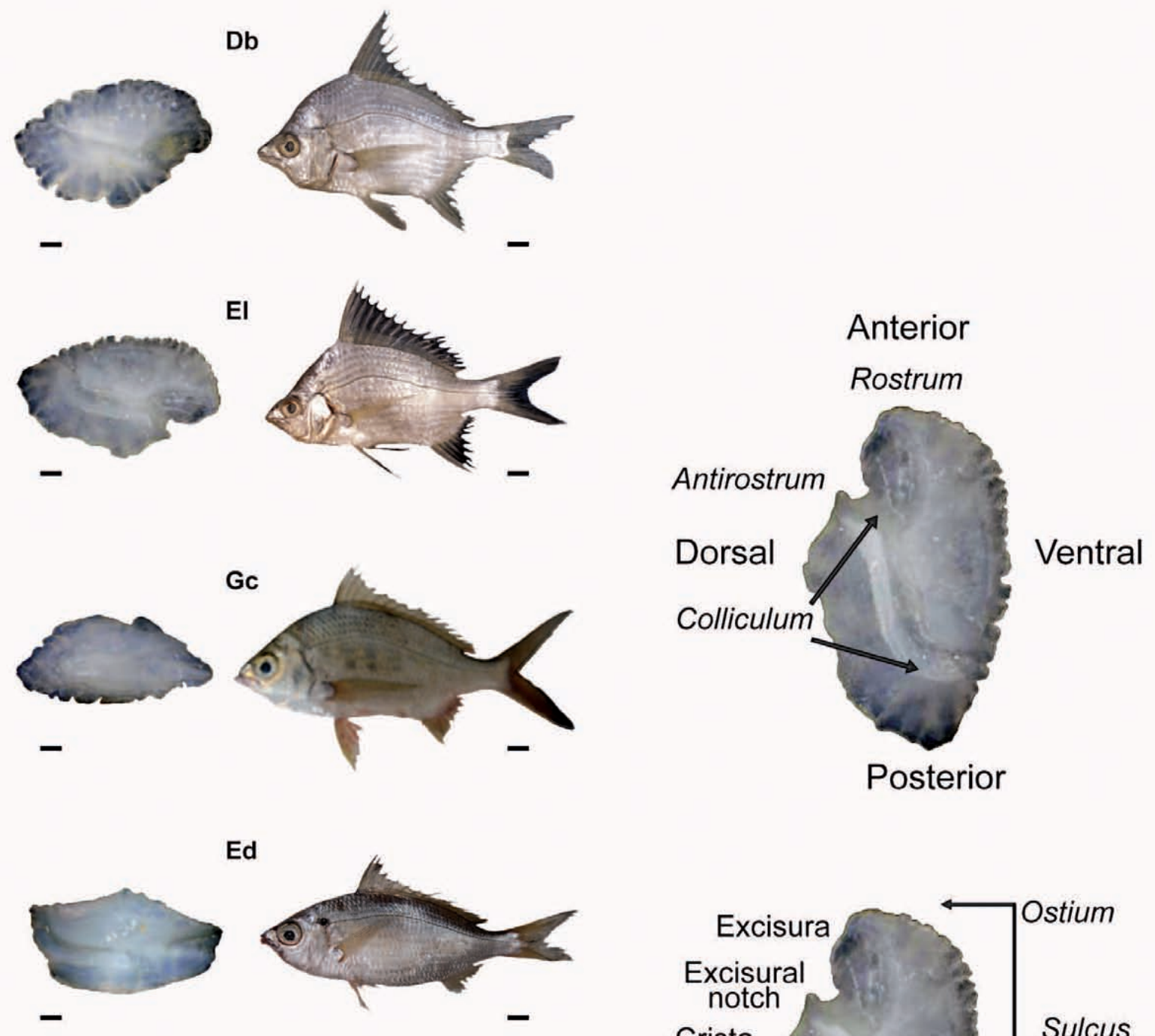

Ee
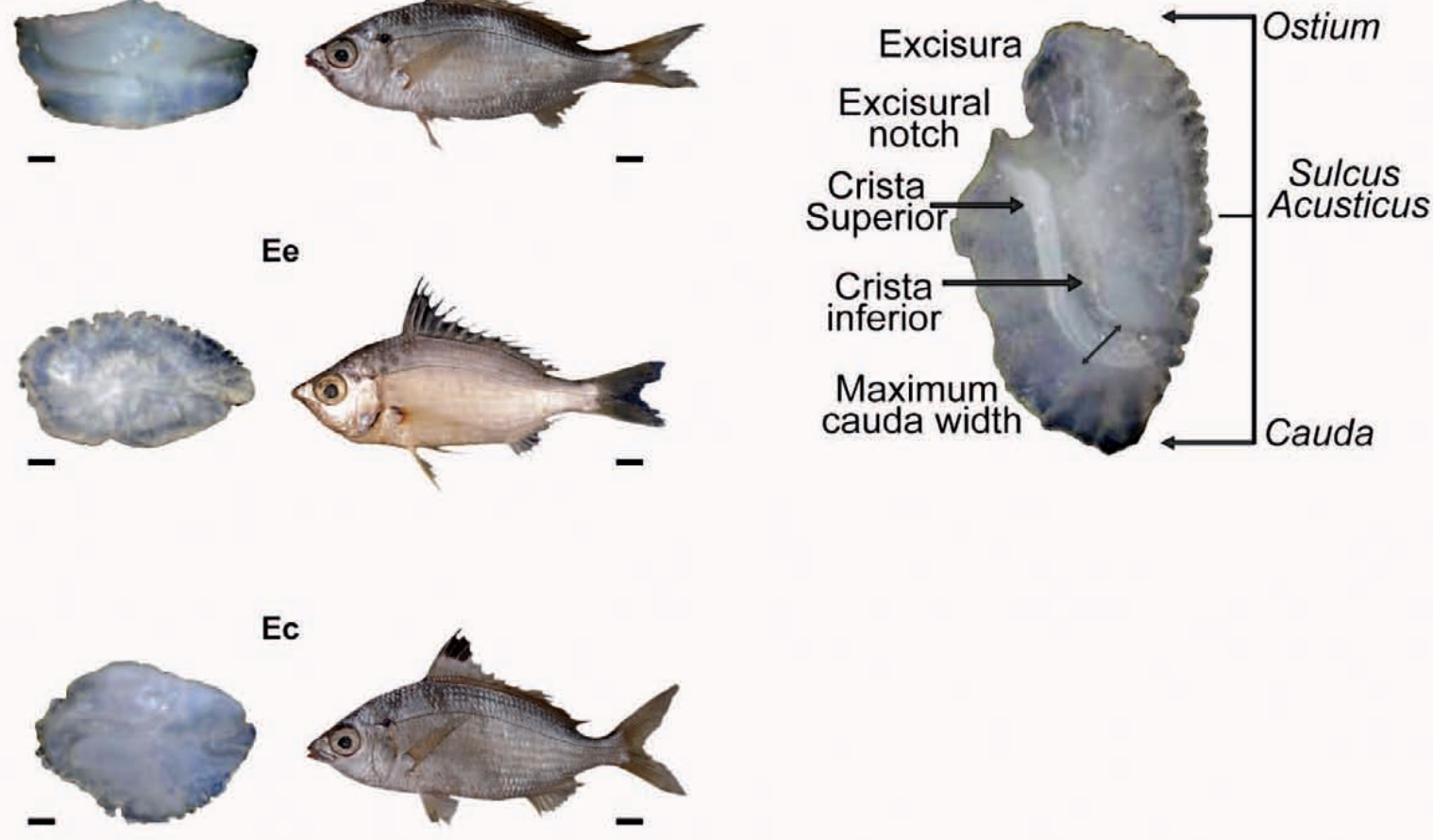

Fig. 2. Morphology of sagittae in six species of the fish family Gerreidae, indicating terminology used in the study; The sulcus acusticus is facing the observer (right sagittae per species; the left sagitta with terminology, modified from Tuset et al. 2003a); $\mathrm{Db}=$ Diapterus brevirostris, El $=$ Eugerres lineatus, Gc $=$ Gerres cinereus, $\mathrm{Ed}=$ Eucinostomus dowii, $\mathrm{Ee}=$ Eucinostomus entomelas, $\mathrm{Ec}=$ Eucinostomus currani; Scale bar for otoliths $=1 \mathrm{~mm}$, and $1 \mathrm{~cm}$ for fish 
cular. Sulcus acusticus: ostial to medium. Ostium: rectangular. Cauda: slightly curved. Anterior region: angled. Proximal margin: lobed. Dorsal margin: serrate. Summary of ratios: cauda length / ostium length $(\mathrm{CL} / \mathrm{OL})=1.313$; ostium length / ostium width $(\mathrm{OL} / \mathrm{OW})=1.229$; and cauda length / rostrum width $(\mathrm{CL} / \mathrm{RW})=1.607$.

Eugerres lineatus. Otolith shape: oval. Sulcus acusticus: ostial to medium. Ostium: rectangular. Cauda: slightly curved. Anterior region: angled. Proximal margin: lobed. Dorsal margin: dentate. Remarks: Some specimens showed deformations in the posterior region. Summary of ratios: cauda length / ostium length $(\mathrm{CL} / \mathrm{OL})=1.413$; ostium length / ostium width $(\mathrm{OL} / \mathrm{OW})=1.208$; and cauda length / rostrum width $(\mathrm{CL} / \mathrm{RW})=1.684$.

Eucinostomus dowii. Otolith shape: semicircular. Sulcus acusticus: ostial to medium. Ostium: funnel-like. Cauda: strongly curved. Anterior region: truncated. Proximal margin: sinuous. Dorsal margin: sinuous to serrated. Summary of ratios: cauda length / ostium length $(\mathrm{CL} / \mathrm{OL})=2.488$; ostium length / ostium width $(\mathrm{OL} / \mathrm{OW})=1.415$; and cauda length / rostrum width $(\mathrm{CL} / \mathrm{RW})=3.474$.

Eucinostomus entomelas. Otolith shape: semicircular. Sulcus acusticus: ostial to medium. Ostium: rectangular. Cauda: slightly curved. Anterior region: angled. Proximal margin: lobed. Dorsal margin: serrated. Summary of ratios: cauda length / ostium length $(\mathrm{CL} / \mathrm{OL})=3.348$; ostium length / ostium width $(\mathrm{OL} / \mathrm{OW})=1.159$; and cauda length / rostrum width $(\mathrm{CL} / \mathrm{RW})=3.832$.

Eucinostomus currani. Otolith shape: oval. Sulcus acusticus: ostial to medium. Ostium: rectangular. Cauda: slightly curved. Anterior region: angled. Proximal margin: lobed. Dorsal margin: dentate. Comments: dorsal margin serrations were observed in specimens larger than $40 \mathrm{~mm}$ SL. Summary of ratios: cauda length / ostium length $(\mathrm{CL} / \mathrm{OL})=2.528$; ostium length / ostium width $(\mathrm{OL} / \mathrm{OW})=1.251$; and cauda length / rostrum width $(\mathrm{CL} / \mathrm{RW})=3.049$.

Gerres cinereus. Otolith shape: oblong. Sulcus acusticus: ostial to medium. Ostium: funnel-like. Cauda: strongly curved. Anterior region: angulated. Proximal margin: sinuous. Dorsal margin: sinuous. Remarks: proximal margin presents a projection that is directed toward the external face of the otolith, like a flap. Summary of ratios: cauda length / ostium length $(\mathrm{CL} / \mathrm{OL})=2.118$; ostium length / ostium width $(\mathrm{OL} / \mathrm{OW})=1.261$; and cauda length / rostrum width $(\mathrm{CL} / \mathrm{RW})=2.664$.

FQT was used to compare the data set for each of species $(n=6)$ based on all sulcus proportions. The Friedman's Q statistics $(P<0.159, \alpha=0.05$; DF $=5)$ suggests that there was no difference among sulcus acusticus proportions per species (e.g., samples were not significantly different).

To apply the CDA, and assure independence among otolith descriptors (e.g., size parameters and shape indices) we performed a preliminary pair wise correlation analysis among all variables. Thus, strongly correlated variables $(r>0.9, P<0.05)$ were excluded from the analysis to avoid redundancy. The results showed that of the twenty three descriptors only ten are not correlated at 5\% significance level: diameter maximum (Dmx), ratio maximum (Rmx), rectangularity, otolith length (Lo), area (Ao), perimeter (Po), roundness, Feret length ( $\mathrm{Fl})$, Feret maximum (Fmx), and form-factor (Table 3).

Five discriminant functions produced were significant for discriminating the six gerreid species using ten descriptors of otoliths. The first three functions account for $93 \%$ of the variation (e.g., F1 $(40 \%): \lambda=0.006$, $P<0.001 ; r^{*}=0.905 ;$ F2 (33\%): $\lambda=0.034, P<0.001$; $r^{*}=0.885$; F3 (20\%): $\left.\lambda=0.156, P<0.001\right) ; r^{*}=0.831$, while the discriminant functions F4 and F5 made a negligible contribution and therefore, were not considered $\left(r^{*}=0.612\right.$ and $r^{*}=0.443$, respectively). Interspecific discriminant analysis of otolith descriptors demonstrated that $90 \%$ (207) from total of sagittae (230) were correctly classified, ranging from $100 \%$ in E. currani to $76 \%$ in D. brevirostris (Table 4). Thus, misclassification rates varied between $0 \%$ (E. currani) and 24\% (D. brevirostris). The Cohen's kappa indicates that a classification efficiency of $88 \%$ better than would have occurred by chance alone $(\kappa=0.879$; standard error $=0.024 ; 95 \%$ confidence interval $=0.832$ to $0.926 ; Z=36.6, P<0.001$ ). Also the $G$-test indicated that otoliths were assigned to the correct species at rates significantly greater than would be expected by chance $(G=669.811$; DF $=25, P<0.000)$.

Score plots for the first three discriminant functions show a separation between the six species although some overlapping can be noticed, all quadratic Mahalanobis distances and species centroids were significant $(P<0.001)$ (Fig. 3). Among all descriptors, only diameter maximum and ratio maximum were not significant $(P<0.57$ and $P<0.31$, respectively). Otolith descriptors with highest contribution to eigenvalues were (standardized coefficients in parentheses): rectangularity $(-24.7)$, otolith length $(-17.9)$, and roundness $(-8.9)$ for F1; rectangularity $(-21.1)$, Feret length $(-13.97 .1)$, and roundness $(5.8)$ for $F 2$, and rectangularity $(-20.6)$, Feret length (-13.9), and roundness (-8.5) for F3.

\section{DISCUSSION}

We found no studies for otoliths of the family Gerreidae, although they were synthetically treated in a study for selected west Atlantic species (Lemos et al. 1993). This family has historically been characterized by the complexity of its

Table 2

Otolith shape indices established from morphometric measurements taken on the mesial surface of each sagittae by species (see Tuset et al. 2003b)

\begin{tabular}{lc}
\hline Shape indices & Formulae \\
\hline${ }^{*}$ Roundness & $(4 \mathrm{Ao})\left(\pi \mathrm{Fl}^{2}\right)^{-1}$ \\
Circularity & $\mathrm{Po}^{2} \mathrm{Ao}^{-1}$ \\
Ellipticity & $(\mathrm{Fl}-\mathrm{Fw})(\mathrm{Fl}+\mathrm{Fw})^{-1}$ \\
${ }^{*}$ Rectangularity & $\mathrm{Ao}(\mathrm{FlFw})^{-1}$ \\
${ }^{*}$ Form factor & $(4 \pi \mathrm{Ao}) \mathrm{Po}^{-2}$ \\
\hline
\end{tabular}

*Not correlated $(\mathrm{P}<0.05)$. 


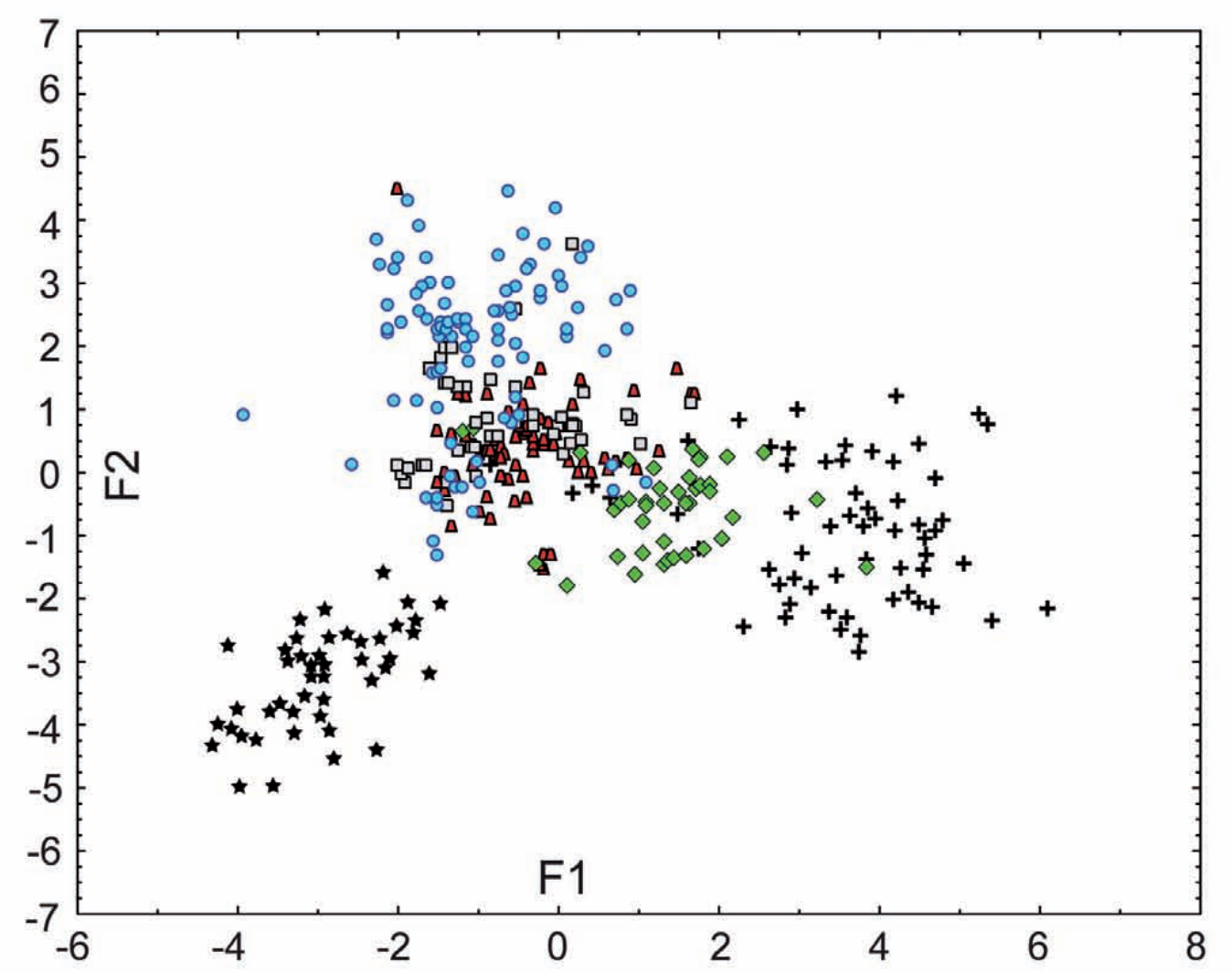

$\circ \mathrm{Db}$
$\square \mathrm{El}$
$\diamond \mathrm{Ed}$

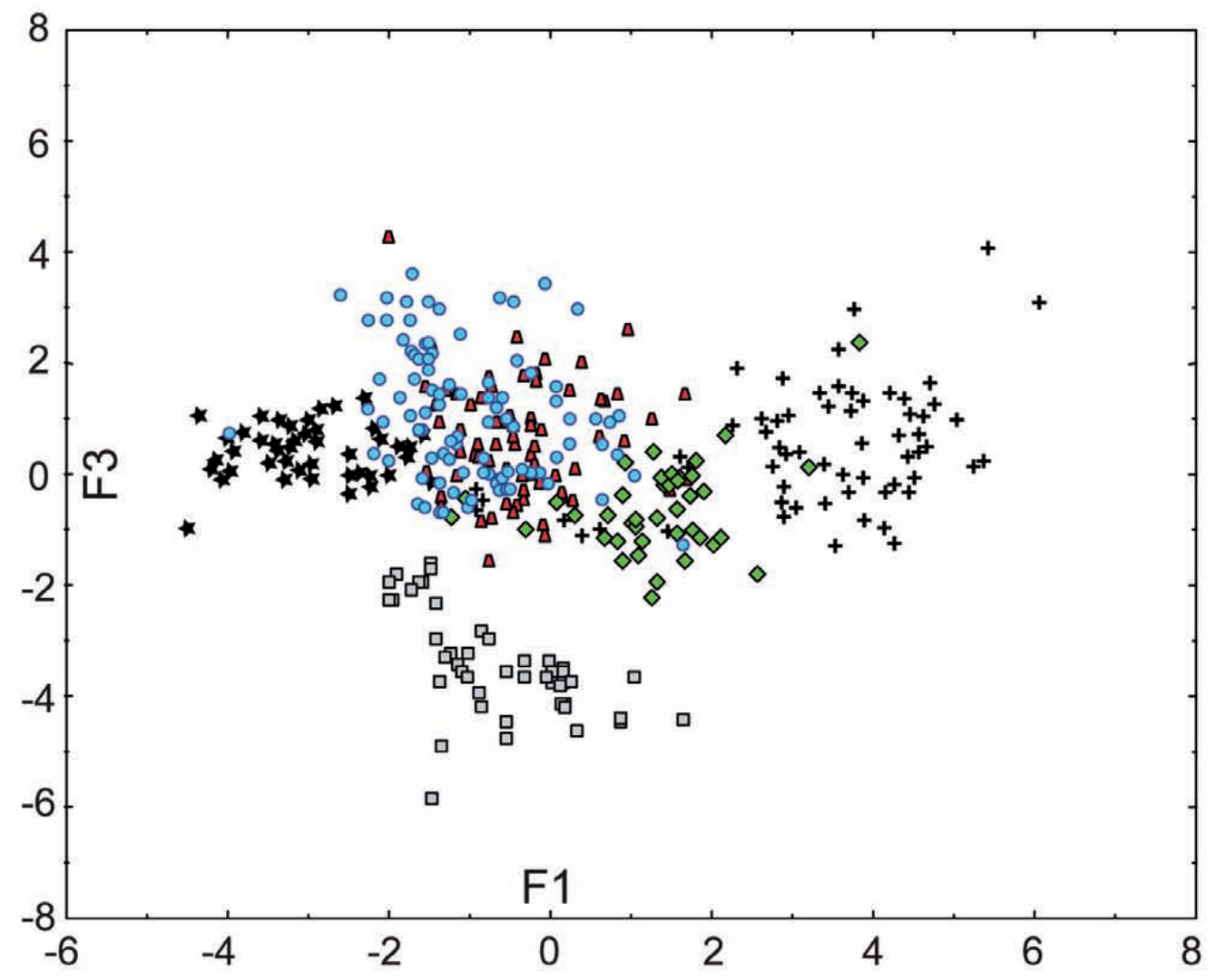

Fig. 3. Scatter plots of first (F1) and second (F2), and first (F1) and third (F3) discriminant functions; Canonical discriminant analysis using ten otolith shape and size descriptors of the six species of Gerreidae; The first discriminant axis (F1) explains 40\%, the second axis (F2) 33\%, and the third axis (F3) 20\% of the variation; $\mathrm{Db}=$ Diapterus brevirostris, $\mathrm{El}=$ Eugerres lineatus, $\mathrm{Ed}=$ Eucinostomus dowii, Ee $=$ Eucinostomus entomelas, $\mathrm{Ec}=$ Eucinostomus currani, $\mathrm{Gc}=$ Gerres cinereus 
taxonomy, both at generic and specific levels (Matheson and McEachran 1984), primarily due to morphological plasticity in some taxa and to uncertain definitions of valid genera. Hence, currently taxonomy within the family Gerreidae is under considerable debate. Another consideration to be mentioned is that the majority of taxonomic reviews (as graduate thesis) about Gerreidae genera have not been published (Curran unpublished*, Zahuranec unpublished $^{* *}$, Deckert unpublished ${ }^{* * *}$ (partially), Matheson unpublished ${ }^{* * * *}$ (partially), De La CruzAgüero unpublished ${ }^{* * * *}$, Burnes-Romo unpublished ${ }^{* * * * *}$ ), although none of them have studied otoliths.

The majority of descriptive studies on fish otolith provide subjective descriptions without an objective framework for comparisons. These descriptions are not standardized (e.g., not related to universal forms of recognition, as could be geometrical shapes: square, rectangle, circle, and so on). Otolith morphology descriptions provided in this study is presented for the first time for the six included Gerreidae species, following a standardized terminology (Volpedo and Echeverría 2000). Usefulness of the employed descriptors is shown in the classification rate of CDA.

Moreover, morphometric properties of sulcus acusticus produced no significant results when comparing mean proportions among gerreid species, despite the demonstrated interspecific differences in other fish species (Torres et al. 2000b, Tuset et al. 2003a), which may be adaptations of the different sizes of fish to environmental conditions occurring at different depths (Lombarte 1992).
This is not the case for Gerreidae species in present research, possibly due to the size range used and shallowness of commercial catches. However, there are certain patterns in proportions CL / OL and CL / RW of taxa that should be investigated: higher values in genus Eucinostomus, intermediate values in $G$. cinereus, and lower values in species of Diapterus and Eugerres. This morphometric pattern corresponds, to some extent, with the taxonomic and phylogenetic arrangements (as discussed below).

CDA results show that this set of morphological variables of otoliths produced a good discrimination among all considered species. Besides, morphological affinity between species corresponds to the current taxonomic arrangement, except for E. currani, as shown in the phenogram based on quadratic Mahalanobis distances (Euclidean distance $=75$; Fig. 4). This morphological affinity is also close to the two proposed phylogenetic clades based on molecular data for the American gerreid genera: clade 1: Eucinostomus / Gerres and clade 2: Diapterus / Eugerres (see Ruiz-Carus and Uribe-Alcocer 2003, Chen et al. 2007), and agreeing with the same two morphological assemblages in taxonomic keys, characterized by the by the shape of preopercle and preorbital bone (Bussing 1995).

Actual separation rate in CDA with otoliths (93\% considering the first three discriminant functions) is similar to several CDA's reports for gerreid species although using variables of body morphology: $97 \%$ for Eucinostomus spp. in the Pacific coast (De La Cruz Agüero and Galvan-

Table 3

Mean values of the main otolith descriptors (not correlated at 5\% significance level) obtained from morphometric measurements of the fish family Gerreidae taken on the lateral view of each sagittae (standard deviation in parentheses)

\begin{tabular}{lcccccc}
\hline \multirow{2}{*}{ Descriptor } & \multicolumn{7}{c}{ Species } \\
\cline { 2 - 7 } & $\mathrm{Db}$ & $\mathrm{El}$ & $\mathrm{Ed}$ & $\mathrm{Ee}$ & $\mathrm{Ec}$ & $\mathrm{Gc}$ \\
\hline Dmx & $8.11(0.69)$ & $7.27(0.84)$ & $6.95(0.38)$ & $5.30(0.35)$ & $6.81(0.61)$ & $6.96(0.81)$ \\
Rmx & $4.14(0.86)$ & $3.76(0.43)$ & $3.64(0.21)$ & $2.73(0.19)$ & $3.48(0.40)$ & $3.65(0.42)$ \\
Po & $24.4(2.41)$ & $22.9(2.95)$ & $19.7(1.21)$ & $16.3(1.44)$ & $20.4(2.10)$ & $20.2(2.02)$ \\
Lo & $8.06(0.70)$ & $7.29(0.83)$ & $7.0(0.37)$ & $5.30(0.35)$ & $6.8(0.60)$ & $7.1(0.82)$ \\
Ao & $28.8(4.24)$ & $21.9(3.42)$ & $19.5(1.82)$ & $14.4(1.71)$ & $20.1(3.10)$ & $16.9(3.82)$ \\
Fmx & $8.14(0.70)$ & $7.36(0.83)$ & $7.03(0.38)$ & $5.32(0.34)$ & $6.88(0.60)$ & $7.10(0.82)$ \\
Fl & $6.58(0.51)$ & $5.88(0.51)$ & $5.59(0.25)$ & $4.54(0.28)$ & $5.50(0.40)$ & $5.34(0.58)$ \\
Ff & $1.99(0.19)$ & $1.66(0.15)$ & $2.13(0.19)$ & $1.67(0.19)$ & $1.87(0.19)$ & $2.53(0.28)$ \\
Rd & $1.66(0.20)$ & $1.92(0.35)$ & $1.58(0.10)$ & $1.47(0.16)$ & $1.69(0.21)$ & $1.96(0.24)$ \\
Rc & $0.71(0.02)$ & $0.68(0.03)$ & $0.72(0.02)$ & $0.70(0.02)$ & $0.69(0.02)$ & $0.70(0.02)$ \\
\hline Acronyyyyyy
\end{tabular}

Acronyms for species: $\mathrm{Db}=$ Diapterus brevirostris, $\mathrm{El}=$ Eugerres lineatus, $\mathrm{Ed}=$ Eucinostomus dowii, Ee $=$ Eucinostomus entomelas, $\mathrm{Ec}=$ Eucinostomus currani, $\mathrm{Gc}=$ Gerres cinereus $; \mathrm{Dmx}=$ diameter maximum, $\mathrm{Rmx}=$ ratio maximum, $\mathrm{Rc}=$ rectangularity, $\mathrm{Lo}=$ otolith length, $\mathrm{Ao}=$ area, $\mathrm{Po}=$ perimeter, $\mathrm{Rd}=$ roundness, $\mathrm{Fl}=$ Feret length, $\mathrm{Fmx}=$ Feret maximum, $\mathrm{Ff}=$ form-factor.

\footnotetext{
${ }^{*}$ Curran H.W. 1942. A systematic revision of the gerreid fishes referred to the genus Eucinostomus, with a discussion of their distribution and speciation. PhD Dissertation. University of Michigan, Ann Arbor, MI, USA.

${ }^{* *}$ Zahuranec B.J. 1967. The Gerried fishes of the genus Eucinostomus in the eastern Pacific. MSc Dissertation, University of California, San Diego, CA, USA.

${ }^{* * *}$ Deckert G.D. 1973. A systematic revision of the genera Diapterus and Eugerres: with the description of a new genus, Schizopterus (Pisces: Gerreidae). MSc Dissertation. Northern Illinois University, DeKalb, IL, USA.

${ }^{* * * * *}$ Matheson R.E. 1983. Taxonomic studies of the Eucinostomus argenteus complex (Pisces: Gerreidae). PhD Dissertation. Texas A\&M University, College Station, TX, USA.

${ }^{* * * * *}$ De La Cruz-Agüero J. 2001. Sistemática y Biogeografía del género Eucinostomus (Teleostei: Gerreidae). PhD Dissertation, Centro Interdisciplinario de Ciencias Marinas, Instituto Politécnico Nacional, La Paz, Baja California Sur, México.

****** Burnes-Romo L.A. 2009. Revision del estatus taxonómico de Gerres cinereus (Walbaum, 1972) (Teleostei: Gerreidae). MSc Dissertation. Centro Interdisciplinario de Ciencias Marinas, Instituto Politécnico Nacional, La Paz, Baja California Sur, México.
} 
Magaña 1993) and 96\% and 93\% for Pacific and Atlantic species of Eugerres, respectively (González Acosta et al. 2005, 2007). In other studies the classification accuracy obtained using otolith descriptors has varied between $70 \%$ and $95 \%$ (Tuset et al. 2006), indicating that otolith morphology can be used for identifying and separating Gerreidae species and it is likely that an individual is better characterized by its two otoliths rather than by only one of them (see Morat et al. 2012).

Although it has been established that otolith shape is markedly species-specific (L'Abée-Lund 1988, L'AbéeLund and Jensen 1993), it is also known that there are external driving forces acting on otoliths shape, whatever the species (Lord et al. 2012) including: age, sex, size, food availability, substrate, water temperature, as well as other

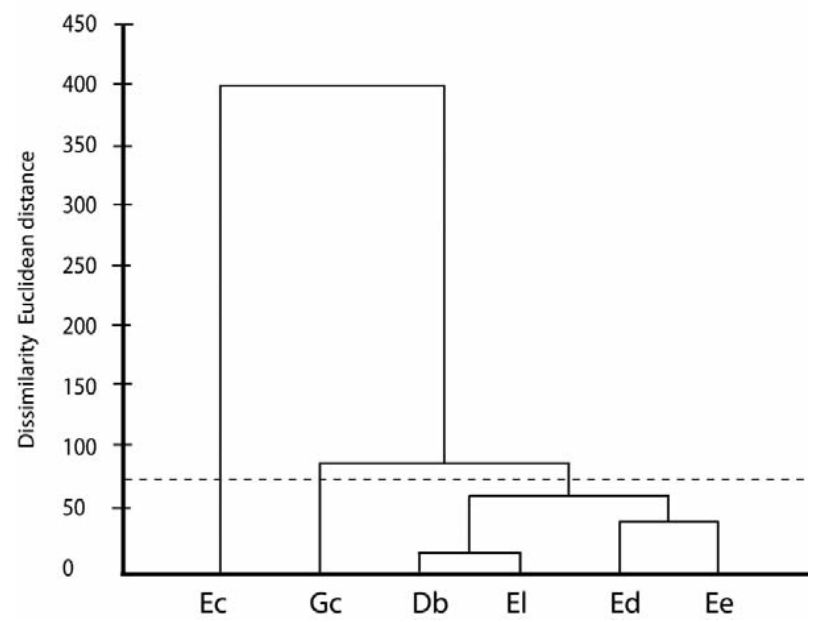

Fig. 4. Dendrogram indicating the phenotypic relationship from the otolith morphology (shape and size data) for Gerreidae species: Ec = Eucinostomus currani, $\mathrm{Gc}=$ Gerres cinereus $\mathrm{Db}=$ Diapterus brevirostris, $\mathrm{El}=$ Eugerres lineatus, Ed = Eucinostomus dowii, $\mathrm{Ee}=$ Eucinostomus entomelas; Dissimilarity based on the Euclidian distance of Mahalanobis distance values, grouping by hierarchical cluster analysis (UPGMA) biological and environmental factors, linked to the species and geographical sites (Tuset et al. 2003a). In the presently reported study, considering that some of these factors are related to sample locations along the Pacific coast of Mexico, and that our analyses were made regardless of sex and minimizing size effect considering mostly adult specimens, there may be a confounding effect increasing the misclassification rate in some species (e.g., D. brevirostris: $24 \%$ and G. cinereus: $21 \%$ ); Table 4). Another possibility could have been an inadequate sample size in that species; according to the criterion that relates the number of variables with the number of individuals (Junquera and Peréz-Gándaras 1993).

Nevertheless, we can conclude that otolith morphology can be used for separation of gerreid species through CDA. Otoliths descriptors here studied (e.g., rectangularity, roundness, otolith length, Feret length, and CL / OL and CL / RW ratios) can also be used as additional features to those already used for proper taxonomic identification, with possible implications of phylogenetic value. For further research on otolith morphology of Gerreidae, would be desirable increasing the number of sagittae per species, and the use of geometric morphometry (e.g., contour analysis) because it might increase the discrimination power and precision of species classifications (Chen et al. 2011).

\section{ACKNOWLEDGEMENTS}

We thank V.M. Cota, J.G. Chollet, F.J. Vergara, A. Martínez, J.A. Payán, and J.A. Medina for their help in the field work, and to M. DiazSantana for improving the English. Funding for this report was provided by Secretaría de Investigación y Posgrado, Instituto Politécnico Nacional (SIP-IPN). JDA, FJGR and GDA are Comisión para el Fomento de las Actividades Académicas (COFAA-IPN) and Estímulo al Desempeño de los Investigadores (EDI-IPN) fellows. JDA and FJGR appreciate the support of the Sistema Nacional de Investigadores (SNI-CONACyT). BPDM received grants from the Programa Institucional de Formación de Investigadores (PIFI-IPN) and Consejo Nacional de Ciencia y Tecnología (CONACyT).

Table 4

Classification matrix as a result of canonical discriminant analysis testing for differences between analyzed species of the fish family Gerreidae based on ten sagittal otolith shape and size descriptors

\begin{tabular}{|c|c|c|c|c|c|c|c|c|}
\hline \multirow{2}{*}{ Actual group } & \multicolumn{6}{|c|}{ Predicted group } & \multirow{2}{*}{ SBS } & \multirow{2}{*}{$\begin{array}{l}\mathrm{CC} \\
{[\%]}\end{array}$} \\
\hline & $\mathrm{Db}$ & $\mathrm{El}$ & Ed & $\mathrm{Ee}$ & Ec & Gc & & \\
\hline $\mathrm{Db}$ & $\underline{28}$ & 0 & 0 & 9 & 0 & 0 & (37) & 75.67 \\
\hline El & 1 & $\underline{35}$ & 0 & 0 & 0 & 0 & (36) & 97.22 \\
\hline Ed & 0 & 0 & $\underline{20}$ & 0 & 0 & 1 & (21) & 95.232 \\
\hline $\mathrm{Ee}$ & 1 & 0 & 1 & $\underline{41}$ & 0 & 0 & (43) & 95.34 \\
\hline Ec & 0 & 0 & 0 & 0 & $\underline{45}$ & 0 & (45) & 100 \\
\hline Gc & 0 & 0 & 5 & 5 & 0 & $\underline{38}$ & (48) & 79.16 \\
\hline Total & 30 & 35 & 26 & 55 & 45 & 39 & $(230)$ & 90.43 \\
\hline
\end{tabular}

Acronyms for species: $\mathrm{Db}=$ Diapterus brevirostris, $\mathrm{El}=$ Eugerres lineatus, $\mathrm{Ed}=$ Eucinostomus dowii, Ee $=$ Eucinostomus entomelas, Ec = Eucinostomus currani, Gc = Gerres cinereus; $\mathrm{SBS}=$ sagittae by species; $\mathrm{CC}=$ correct classification percentage by species; Underlined: quantity of correctly classified otoliths for each species; sample sizes in parentheses; Overall classification success of 90.43\%; Cohen's kappa $=0.879, P<0.001 ; G$-test $=669.8, P<0.000$. 


\section{REFERENCES}

Aguirre-León A., Yáñez-Arancibia A. 1986. Las mojarras de la Laguna de Términos: taxonomía, biología, ecología y dinámica trófica (Pisces: Gerreidae). Anales del Instituto de Ciencias del Mar y Limnología, Universidad Nacional Autónoma de México 13 (1): 369-444.

Begg G.A., Brown W. 2000. Stock identification of haddock Melanogrammus aeglefinus on Georges Bank based on otolith shape analysis. Transactions of the American Fisheries Society 129 (4): 935-945.

DOI: 10.1577/1548-8659(2000)129<0935:SIOHMA >2.3.CO;2

Bussing W.A. 1995. Gerreidae. Pp. 1114-1128. In: Fisher W., Krupp F., Schneider W., Sommer C., Carpenter K.E., Niem V.H. (eds.) Guía para la identificación de especies para los fines de la pesca. Pacífico Centro-Oriental. FAO, Roma.

Chen W., Al-Husaini M., Beech M., Al-Enezi K., Rajab S., Husain H. 2011. Discriminant analysis as a tool to identify catfish (Ariidae) species of the excavated archaeological otoliths. Environmental Biology of Fishes 90 (3): 287-299. DOI: $10.1007 / \mathrm{s} 10641-010-9742-6$

Chen W.-J., Ruiz Carus R., Ortí G. 2007. Relationships among four genera of mojarras (Teleostei: Perciformes: Gerreidae) from the western Atlantic and their tentative placement among percomorph fishes. Journal of Fish Biology 70 (Suppl. sb): 202-218.

DOI: $10.1111 / j .1095-8649.2007 .01395 . x$

De La Cruz-Agüero J., Galvan-Magaña F. 1993. Morphological discrimination of Eucinostomus spp. from the Pacific coast of Mexico. Bulletin of Marine Science 52 (2): 819-824.

Eschmeyer W.N. (ed.) 2012. Catalog of Fishes. California Academy of Sciences. (http://research.calacademy.org/ research/ichthyology/catalog/fishcatmain.asp) Electronic version accessed on 10 May 2012.

Froese R., Pauly D. (Eds) 2012. FishBase. World Wide Web electronic publication. www.fishbase.org, version (10/2012).

González-Acosta A.F., De La Cruz-Agüero J., CastroAguirre J.L. 2005. A review of eastern Pacific species of the genus Eugerres (Perciformes: Gerreidae). Bulletin of Marine Science 76 (3): 661-673.

González-Acosta A.F., De La Cruz-Agüero J., CastroAguirre J.L. 2007. A review of the marine western Atlantic species of the genus Eugerres (Perciformes: Gerreidae). Bulletin of Marine Science 80 (1): 109-124.

Junquera S., Pérez-Gándaras G. 1993. Population diversity in Bay of Biscay anchovy (Engraulis encrasicolus L. 1758) as revealed by multivariate analysis of morphometric and meristic characters. ICES Journal of Marine Science 50 (4): 383-391. DOI: $10.1006 /$ jmsc. 1993.1043

Klecka W.R. 1980. Discriminant analysis. Sage University Papers, Series on Quan- titative Applications in the Social Sciences, Beverly Hills, CA, USA.

L'Abée-Lund J.H. 1988. Otolith shape discriminates between juvenile Atlantic salmon, Salmo salar L., and brown trout, Salmo trutta L. Journal of Fish Biology 33 (6): 899-903. DOI: $10.1111 /$ j.1095-8649.1988.tb05538.x

L'Abée-Lund J.H., Jensen A.J. 1993. Otoliths as natural tags in the systematics of salmonids. Environmental Biology of
Fishes 36 (4): 389-393.

DOI: $10.1007 / \mathrm{BF} 00012418$

Lachenbruch P.A., Mickey M.R. 1968. Estimation of error rates in discriminant analysis. Technometrics 10 (1): 1-11. DOI: 10.1080/00401706.1968.10490530

Lemos B., Correa M., Abilhoa V. 1993. Catálogo de otólitos de Gerreidae (Osteichthyes-Perciformes) do Litoral do Estado do Paraná. Neritica 7: 109-117.

Lombarte A.J. 1992. Changes in otolith area: sensory area ratio with body size and depth. Environmental Biology of Fishes 33 (4): 405-410. DOI: $10.1007 / \mathrm{BF} 00010955$

Lombarte A.J., Lleonart J. 1993. Otolith size changes related with body growth, habitat depth and temperature. Environmental Biology of Fishes 37 (3): 297-306. DOI: $10.1007 / \mathrm{BF} 00004637$

Lombarte A., Rucabado J., Matallanas J., Lloris D. 1991. Taxonomía numérica de Nototheniidae en base a la forma de los otolitos. Scientia Marina 55 (2): 413-418.

Lord C., Morat F., Lecomte-Finiger R., Keith P. 2012. Otolith shape analysis for three Sicyopterus (Teleostei: Gobioidei: Sicydiinae) species from New Caledonia and Vanuatu. Environmental Biology of Fishes 93 (2): 209-222. DOI: 10.1007/s10641-011-9907-y

Matheson R.E.jr., McEachran J.D. 1984. Taxonomic studies of the Eucinostomus argenteus complex (Pisces: Gerreidae): preliminary studies of external morphology. Copeia 1984 (4): 893-902.

Morat F., Letourneur Y., Nérini D., Banaru D., Batjakas I.E. 2012. Discrimination of red mullet populations (Teleostean, Mullidae) along multi-spatial and ontogenetic scales within the Mediterranean basin on the basis of otolith shape analysis. Aquatic Living Resources 25 (1): 27-39. DOI: $10.1051 / \mathrm{alr} / 2011151$

Neves A., Sequeira V., Farias I., Vieira A.R., Paiva R., Serrano Gordo L. 2011. Discriminating bluemouth, Helicolenus dactylopterus (Pisces: Sebastidae), stocks in Portuguese waters by means of otolith shape analysis. Journal of the Marine Biological Association of the United Kingdom 91 (Special issue 06): 1237-1242. DOI: $10.1017 / \mathrm{S} 002531541000189 \mathrm{X}$

Nolf D. 1995. Studies on fossil otoliths. The state of the art. Pp. 513-544. In: Secor D.H., Dean J.M., Campana S.E. (eds.) Recent developments in fish otolith research. University of South Carolina Press, Columbia, SC, USA.

Pertusa J.F. 2003. Técnicas de análisis de imagen: Aplicaciones en biología. Universitat de Valéncia, Aldaia, Spain.

Ponton D. 2006. Is geometric morphometrics efficient for comparing otolith shape of different fish species? Journal of Morphology 267 (6): 750-757.

DOI: $10.1002 /$ jmor.10439

Pothin K., González-Salas C., Chabanet P., Lecomte-Finiger R. 2006. Distinction between Mulloidichthys flavolineatus juveniles from Reunion Island and Mauritius Island (southwest Indian Ocean) based on otolith morphometrics. Journal of Fish Biology 69 (1): 38-53.

DOI: $10.1111 / \mathrm{j} .1095-8649.2006 .01047 . \mathrm{x}$

Radhakrishnan K.V., Liu M., He W., Murphy B.R., Xie S. 2010. Otolith retrieval from faeces and reconstruction of prey- 
fish size for Great Cormorant (Phalacrocorax carbo) wintering at the East Dongting Lake National Nature Reserve, China. Environmental Biology of Fishes 89 (3-4): 505-512. DOI: 10.1007/s10641-010-9685-y

Ruiz-Carus R., Uribe-Alcocer M. 2003. Phylogenetic assessment of Eucinostomus gula, Eugerres plumieri, and Diapterus auratus (Pisces; Gerreidae) based on allozyme and mtDNA analyses. Caribbean Journal of Science 39 (1): 109-115.

Smale M.J., Watson G., Hecht T. 1995. Otolith atlas of southern African marine fishes. Ichthyological Monographs of the J.L.B. Smith Institute of Ichthyology, Grahamstown, Republic of South Africa.

Titus K., Mosher J.A., Williams B.K. 1984. Chance-corrected classification for use in discriminant analysis: ecological applications. American Midland Naturalist 111 (1): 1-7.

Torres G.J., Lombarte A.J., Morales-Nin B. 2000a. Sagittal otolith size and shape variability to identify geographical intraspecific differences in three species of the genus Merluccius. Journal of the Marine Biological Association of the United Kingdom 80 (2): 333-342.

DOI: $10.1017 / \mathrm{S} 0025315499001915$

Torres G.J., Lombarte A.J., Morales-Nin B. 2000 b. Variability of the sulcus acusticus in the sagittal otolith of the genus Merluccius (Merluciidae). Fisheries Research 46 (1-3): 5-13.

DOI: $10.1016 / \mathrm{S} 0165-7836(00) 00128-4$

Tuset V.M., Lombarte A., González J.A., Pertusa J.F., Lorente MaJ. 2003a. Comparative morphology of the sagittal otolith in Serranus spp. Journal of Fish Biology 63 (3): 1491-1504. DOI: $10.1111 /$ j.1095-8649.2003.00262.x
Tuset V.M., Lozano I.J., González J.A., Pertusa J.F., GarcíaDíaz M.M. 2003b. Shape indices to identify regional differences in otolith morphology of comber, Serranus cabrilla (L., 1758). Journal of Applied Ichthyology 19 (2): 88-93. DOI: 10.1046/j.1439-0426.2003.00344.x

Tuset V.M., Rosin P.L., Lombarte A.J. 2006. Sagittal otolith shape used in the identification of fishes of the genus Serranus. Fisheries Research 81 (2-3): 316-325.

DOI: $10.1016 /$ j.fishres.2006.06.020

Volpedo A.V., Echeverría D.D. 2000. Catálogo y claves de otolitos para la identificación de peces del Mar Argentino. Editorial Dunken, Buenos Aires, Argentina.

Volpedo A.V., Tombari A.D., Echeverría D.D. 2008. Ecomorphological patterns of the sagitta of Antarctic fish. Polar Biology 31 (5): 635-640.

DOI: $10.1007 / \mathrm{s} 00300-007-0400-1$

Yáñez-Arancibia A. 1980. Taxonomía, ecología y estructura de las comunidades de peces en lagunas costeras con bocas efímeras del Pacifico de México. Anales del Instituto de Ciencias del Mar y Limnología, Universidad Nacional Autónoma de México 2: 1- 306.

Zar J.H. 2009. Biostatistical Analysis. Prentice Hall, Englewood Cliffs, NJ, USA.

Received: 12 May 2012

Accepted: 26 October 2012

Published electronically: 31 December 2012 